\title{
Validation of a Spanish version of the Sleep-Related Breathing Disorder scale of the Pediatric Sleep Questionnaire in children living in a high-altitude city
}

\author{
Maria C. Villalobos-Aguirre ${ }^{1}$, Sonia M. Restrepo-Gualteros ${ }^{1}$, Alberto Peña-Valenzuela ${ }^{1}$, \\ Monica Sossa-Briceño ${ }^{1}$, and Carlos Rodriguez-Martinez ${ }^{2}$ \\ ${ }^{1}$ Universidad Nacional de Colombia \\ ${ }^{2}$ School of Medicine, Universidad El Bosque
}

November 4, 2020

\begin{abstract}
Objectives. We aimed to validate a Spanish version of the Sleep-Related Breathing Disorder scale of the Pediatric Sleep Questionnaire (SRBD-PSQ) in children living in a high-altitude Colombian city. Methods. In a prospective cohort validation study, patients aged between 2 and 18 years who attended the Ear, Nose, and Throat pediatric department of our institution for symptoms related to sleep-related breathing disorders had a baseline visit at enrollment, a second visit the day scheduled for the surgical intervention, and a follow-up visit at least three months after the surgical intervention. In these three visits, we gathered the necessary data for assessing the criterion validity, construct validity, test-retest reliability, internal consistency, and sensitivity to change of the Spanish version of the SRBD-PSQ. Results. In total, 121 patients were included in the analyses. The exploratory factor analysis (generalized least squares method, varimax rotation) yielded a four-factor structure, explaining $65.93 \%$ of the cumulative variance. The intraclass correlation coefficient (ICC) of the measurements was 0.887 (95\% CI: 0.809-0.934), and the Lin concordance correlation coefficient was 0.882 (95\% CI, 0.821-0.943). SRBD-PSQ scores at baseline were significantly higher than those obtained after adeno-tonsillectomy surgery (median [IQR] 11.0 [9.0- 14.0] vs. 4.00 [1.50- 7.0]; $\mathrm{p}<0.0001)$. Cronbach's $\alpha$ was 0.7055 for the questionnaire as a whole. Conclusions. The Spanish version of the SRBD-PSQ has acceptable construct validity, excellent test-retest reliability and sensitivity to change, and adequate internal consistency-reliability when used in pediatric patients living at high altitude with symptoms related to sleep-related breathing disorders.
\end{abstract}

\section{Hosted file}

Main Document.pdf available at https://authorea.com/users/373115/articles/490892-validationof-a-spanish-version-of-the-sleep-related-breathing-disorder-scale-of-the-pediatricsleep-questionnaire-in-children-living-in-a-high-altitude-city

\section{Hosted file}

Table 1.pdf available at https://authorea.com/users/373115/articles/490892-validation-ofa-spanish-version-of-the-sleep-related-breathing-disorder-scale-of-the-pediatric-sleepquestionnaire-in-children-living-in-a-high-altitude-city 